\title{
Effect of Birth-Related Events on Metabolism in Fetal Sheep
}

\author{
HARRIET S. IWAMOTO, ${ }^{1}$ DAVID F. TEITEL, AND ABRAHAM M. RUDOLPH
}

Cardiovascular Research Institute and Departments of Pediatrics, Physiology, Obstetrics, Gynecology, and Reproductive Sciences, University of California, San Francisco, California 94143-0544

\begin{abstract}
At birth, changes in utilization of metabolic substrates occur as the fetus, dependent upon carbohydrates and amino acids available continuously from the placenta, becomes a neonate, dependent primarily upon fat obtained intermittently by suckling. In addition to changes in substrates, at birth, metabolic rate increases dramatically as the activity of several organs and thermoregulatory mechanisms increase. To determine whether metabolic changes are related to certain events that occur at birth, we studied 15 fetal sheep instrumented chronically with vascular catheters and an endotracheal tube at 133 to 137 d gestational age. We measured blood flow with radionuclide-labeled microspheres and arteriovenous concentration differences for oxygen content, blood glucose, and lactate across the placental, cerebral, myocardial, and hindlimb circulations at rest, during in utero ventilation of the fetal lungs with $3 \% \mathrm{O}_{2}$, during in utero ventilation with $100 \% \mathrm{O}_{2}$, and during ventilation with $100 \% \mathrm{O}_{2}$ and umbilical cord occlusion. Ventilation with $3 \% \mathrm{O}_{2}$ decreased oxygen uptake by the fetus and by the cerebral circulation but produced no other significant changes. Ventilation with the low and high oxygen gas mixture reduced glucose uptake by the fetus from the placental circulation dramatically to zero. In contrast, blood glucose concentrations increased and glucose uptake by the fetal brain, heart, and hindlimb were not altered significantly. These data indicate that, for a short time at least, complete cessation of glucose supply to the fetus from the placenta is not associated with decreases in blood glucose concentrations or utilization of glucose by a major portion of the fetal body. (Pediatr Res 30: 158-164, 1991)
\end{abstract}

Oxygen consumption increases abruptly at birth (1-3). Important factors that increase oxygen consumption in the neonate are a decrease in environmental temperature, an increase in muscle activity, and appropriate hormonal stimulation (1,3-7). An increase in oxygen delivery per se does not appear to increase oxygen consumption. Contrary to the notion that the fetus is hypoxemic and fetal oxygen delivery normally limits fetal oxygen consumption, an increase in oxygen delivery to the fetus does not increase fetal oxygen consumption $(8,9)$.

Shortly after birth, certain tissues alter the substrates they utilize. In the fetus, the major substrates consumed are carbohydrates supplied by the mother (2). After birth, the continuous nutrient supply from the placenta ceases. The newborn mobilizes its fat and glycogen reserves, and blood glucose, lactate, and FFA

Received November 20, 1990; accepted April 22, 1991.

Correspondence: Harriet S. Iwamoto, Ph.D., Department of Pediatrics, University of Cincinnati, 231 Bethesda Avenue, ML 541, Cincinnati, OH 45167-0541.

Supported by an NIH Program Project Grant, HL 24056.

${ }^{1}$ Current address: Department of Pediatrics, University of Cincinnati, 231 Bethesda Avenue, ML 541, Cincinnati, OH 45167-0541. concentrations increase (10). Thus, the substrates available change, and several organs utilize fats instead of carbohydrates. Concurrently, the function and metabolic demands of several organs change.

The events that initiate changes in regional oxygen and substrate utilization at birth are not known. Many previous studies that have examined aspects of regional metabolism are based on in vitro measurements of metabolism of tissues derived from fetuses or newborns or upon in vivo measurements of regional metabolism in separate groups of fetal and newborn animals (11-14). In the present study, we examined the immediate effects of ventilation, oxygenation, and umbilical cord occlusion on oxygen, glucose, and lactate fluxes across the umbilical-placental, cerebral, myocardial, and hindlimb circulations in chronically prepared sheep fetuses. In this manner, we measured total oxygen, glucose, and lactate uptake by the fetus and oxygen and substrate utilization by the fetus and individual organs. These measurements yielded an estimate of energy requirements of $80 \%$ of fetal mass, which normally accounts for approximately $64 \%$ of the total fetal oxygen requirement (15) and $85 \%$ of the glucose requirement. Hemodynamic responses to ventilation, oxygenation, and umbilical cord occlusion in these fetuses have been presented in a separate publication (16).

\section{MATERIALS AND METHODS}

Animals and surgical preparation. Before the initiation of these studies, all surgical and experimental procedures were approved by the Animal Care and Use Committee at the University of California, San Francisco. We studied 15 fetal sheep at 133 to $137 \mathrm{~d}$ gestational age. The ewe was fasted for 24 to $36 \mathrm{~h}$ before surgery. After local anesthesia (2\% lidocaine hydrochloride), low spinal or epidural anesthesia was achieved with $4 \mathrm{~mL}$ of $1 \%$ tetracaine hydrochloride (Pontocaine $\mathrm{HCl}$; Breon Laboratories, New York, NY). Polyvinyl catheters (1.3 $\mathrm{mm}$ inner diameter, $2.3 \mathrm{~mm}$ outer diameter) were placed into the descending aorta and inferior vena cava of the ewe. Ten percent dextrose in $0.9 \%$ sodium chloride was infused continuously, and 50 to $100 \mathrm{mg}$ of ketamine hydrochloride (Vetalar; Parke-Davis, Morris Plains, $\mathrm{NJ}$ ) was administered i.v. to the ewe at 15 -min intervals throughout the duration of the surgical procedure. Local anesthetic $(0.25 \%$ lidocaine hydrochloride) was administered before each maternal and fetal skin incision.

Through a midline incision in the abdomen of the ewe, the pregnant horn of the uterus was exposed and polyvinyl catheters were placed in the fetal descending aorta and inferior vena cava. Additional catheters were placed into a main umbilical vein from a peripheral tributary and in the amniotic cavity. The fetal skin and uterine incisions were sutured. A second uterine incision was made overlying the left chest of the fetus. Through a thoracotomy in the 3rd intercostal space, catheters were placed in the ascending aorta from the internal thoracic artery and directly into the left atrium, pulmonary artery, and pleural cavity. In 11 fetuses, a catheter was inserted into the left hemiazygous vein 
and passed into the coronary sinus as previously described (11). The fetal chest was sutured in layers. The fetal neck was exposed through the same uterine incision. A 4.5-mm endotracheal tube, connected by a Y-tube to two 100 -cm lengths of flexible polyvinyl tubing ( $3.2 \mathrm{~mm}$ inner diameter, $6.4 \mathrm{~mm}$ outer diameter), was filled with $0.9 \%$ saline and inserted into the fetal trachea. A polyvinyl catheter was inserted into the external jugular vein and advanced centrally to the superior vena cava. In eight fetuses, a catheter (20-gauge IV cath; Becton Dickinson, Parsippany, NJ) was inserted into the sagittal sinus directly. An inflatable silicone rubber cuff, which did not constrict the umbilical vessels when deflated, was placed around the umbilical cord at the umbilical ring in all fetuses. All incisions were sutured and the vascular catheters were filled with heparin sodium solution $(1000 \mathrm{U} / \mathrm{mL})$ and sealed. All catheters and ventilation tubing were exteriorized to the maternal flank and protected by a cloth pouch. A catheter in the amniotic cavity was connected to the ventilation tubing to allow tracheal fluid to flow freely from the fetus to the amniotic cavity postoperatively. Antibiotics ( $400 \mathrm{mg}$ kanamycin, $1000000 \mathrm{U}$ penicillin) were instilled into the amniotic cavity and injected into the maternal vein on the day of surgery and each day thereafter. The animals were allowed 2 to $3 \mathrm{~d}$ to recover from surgery.

Experimental procedure. On the day of the study, the ewes were brought into the laboratory in a mobile cart and allowed to become accustomed to the surroundings for at least $2 \mathrm{~h}$. Food and water were provided. Fetal blood pressures and heart rate were monitored continuously throughout the experimental period, using Statham P23Db strain-gauge transducers, Beckman R612 (Beckman Instruments, Inc., Palo Alto, CA) or Gould 2800 S polygraphs (Gould, Inc., Cleveland, $\mathrm{OH}$ ), and a cardiotachometer. Blood samples were obtained during the control period and $15 \mathrm{~min}$ after the onset of each of the following conditions: ventilation with $3 \% \mathrm{O}_{2}, 5 \% \mathrm{CO}_{2}$, and $92 \% \mathrm{~N}_{2}$ (ventilation); ventilation with $100 \%$ oxygen (oxygenation); and total occlusion of umbilical blood flow during ventilation with oxygen (occlusion). Blood samples were obtained from the descending aorta for the determination of $\mathrm{pH}, \mathrm{PO}_{2}$, and $\mathrm{PCO}_{2}$, and from the ascending and descending aorta, umbilical vein, coronary sinus, sagittal sinus, and inferior vena cava for the determination of the $\mathrm{Hb}$ concentration, blood oxygen saturation, and glucose and lactate concentrations (model no. 158 blood gas analyzer, Corning Medical, Medfield, MA; model no. OSM2 hemoximeter, Radiometer, Copenhagen, Denmark; models no. 23A and 23L glucose and lactate analyzers, Yellow Springs Instrument Co., Yellow Springs, $\mathrm{OH})$. Arterial blood gas determinations were made at $37^{\circ} \mathrm{C}$ and corrected to $39^{\circ} \mathrm{C}$. Combined ventricular output and blood flow distribution were then determined by injecting two differently labeled $15-\mu \mathrm{m}$ microspheres (selected from ${ }^{57} \mathrm{Co},{ }^{51} \mathrm{Cr},{ }^{153} \mathrm{Gd},{ }^{114} \mathrm{In},{ }^{54} \mathrm{Mn},{ }^{95} \mathrm{Nb},{ }^{113} \mathrm{Sn},{ }^{85} \mathrm{Sr}$, or ${ }^{65} \mathrm{Zn}$; New England Nuclear, Boston, MA) into the inferior vena cava and left atrium while obtaining reference samples at a rate of $3.88 \mathrm{~mL} / \mathrm{min}$ from the descending and ascending aorta and the pulmonary artery. The volume of blood removed was replaced simultaneously with an equal volume of fetal donor or, in rare instances, maternal blood. To ventilate the fetuses, the tubes connected to the endotracheal tube were opened and tracheal fluid was allowed to drain. These tubes were connected to a specially designed positive pressure ventilator. We measured the rate of respiration, peak inspiratory and end expiratory pressures, and tidal volume (Fleisch type no. 00, Medical Inc., Richmond, VA; Validyne model no. DP45-16 pressure transducer and model no. CD15 carrier demodulator, Engineering Corp., Northridge, CA). These values were $50 \pm 9$ breaths/min, $25 \pm 9$ torr, $5 \pm 7$ torr, and $23 \pm 16 \mathrm{~mL}$, respectively, during the ventilation period, and there were no significant changes in these variables throughout the experimental period.

Upon completion of the last set of measurements, the ewe was killed with an i.v. injection of 6 to $10 \mathrm{~g}$ sodium pentobarbital (Euthanasia-6; Veterinary Laboratories, Lexena, KS) and bilat- eral thoracotomy. Combined ventricular output and its distribution were determined as described previously in detail (17). Briefly, the uterus and individual fetal organs were dissected, weighed, and placed in formalin. Fetal weights at time of death averaged $3.57 \pm 0.67 \mathrm{~kg}$. Organs were carbonized in an oven at $350^{\circ} \mathrm{C}$, ground into a coarse powder, placed into plastic vials to a uniform height of $3 \mathrm{~cm}$, and counted in a 1000-channel multichannel pulse-height analyzer (Norland Corp., Fort Atkinson, WI). The activity of each isotope in each organ was determined by the least-squares method described previously (18).

Data analysis. Plasma catecholamine concentrations were determined by electrochemical detection after separation by HPLC (Coulochem Electrochemical Detector; ESA, Bedford, MA). In each assay, a complete internal standard curve was run and the intra- and interassay coefficients of variation for norepinephrine, epinephrine, and dopamine were 1.4, 2.7, and 2.0 and 5.5, 7.8, and $14.0 \%$, respectively. Additional details of the assay have been published (19). Blood flow to fetal organs was calculated as described previously in detail $(17,20)$. Vascular pressures were corrected using amniotic fluid pressure as zero reference. Oxygen content was calculated using the following formula: $\mathrm{O}_{2}$ content $(\mathrm{mL} / \mathrm{dL}$ blood $)=(1.36 \cdot \mathrm{Hb}$ concentration $\cdot$ Hb saturation $)+$ 0.003 . blood $\mathrm{PO}_{2}$. Oxygen and substrate delivery to the fetus was determined as the product of umbilical-placental blood flow and oxygen content, glucose, or lactate concentrations in umbilical venous blood. Oxygen and substrate delivery rates to the brain, heart, and hindlimb were calculated as the product of the relevant blood flow (cerebral hemispheres, left ventricular free wall, or lower carcass, respectively) and oxygen content, glucose, or lactate concentrations in the ascending or descending aorta. Oxygen and substrate consumption by individual vascular beds were calculated as the product of organ blood flow and the arteriovenous oxygen content, glucose, or lactate concentration differences (umbilical venous-descending aorta for the entire fetus; ascending aorta-sagittal sinus for the brain; ascending aorta-carotid sinus for the left ventricle; and the descending aortasubrenal inferior vena cava for the hindlimb). Extraction of oxygen or substrates by a vascular bed was determined by dividing the arteriovenous concentrations difference by the arterial concentration. Substrate oxygen quotients, the fraction of oxygen consumed to completely oxidize a substrate, were calculated by dividing arteriovenous concentration differences for glucose or lactate by the arteriovenous concentration differences for oxygen. This quotient was multiplied by 6 for glucose or 3 for lactate.

Data from one period were compared with data from the previous period by the Mann-Whitney U test, with the understanding that the chance of committing a Type II error with paired data is increased. All data are expressed as mean \pm SD.

\section{RESULTS}

The fetuses in these studies initially had normal arterial blood $\mathrm{pH}$ and gases (Table 1). Ventilation alone had no significant effect on these values. During ventilation with $100 \%$ oxygen, oxygen tension in the descending aorta and oxygen content in the descending and ascending aorta and umbilical vein increased significantly, but arterial $\mathrm{pH}$ and carbon dioxide tension did not change (Table 1).

Fetal blood glucose concentrations were normal and lactate concentrations were somewhat elevated during the control period (Table 1). Ventilation increased blood glucose and lactate concentrations slightly, but only the increase in arterial glucose concentration was significant. Subsequent oxygenation and cord occlusion produced no significant effect on either glucose or lactate concentrations. In the ewes, arterial $\mathrm{pH}, \mathrm{PCO}_{2}, \mathrm{PO}_{2}$, oxygen content, glucose, and lactate values during the control period were in the normal range and were not altered significantly during the experimental period (Table 2).

Plasma concentrations of norepinephrine, epinephrine, and dopamine in the fetal descending aorta were $9.49 \pm 2.08 \mathrm{nmol} /$ 
Table 1. Effect of birth-related events on fetal blood*

\begin{tabular}{|c|c|c|c|c|}
\hline & Control & Ventilation & Oxygenation & Occlusion \\
\hline Descending Ao & (15) & $(15)$ & (15) & (11) \\
\hline $\mathrm{pH}$ & $7.38 \pm 0.06$ & $7.36 \pm 0.06$ & $7.36 \pm 0.07$ & $7.33 \pm 0.12$ \\
\hline $\mathrm{PCO}_{2}(\mathrm{kPa})$ & $7.06 \pm 0.79$ & $7.06 \pm 0.67$ & $6.67 \pm 0.93$ & $7.73 \pm 2.93$ \\
\hline $\mathrm{PO}_{2}(\mathrm{kPa})$ & $2.27 \pm 0.40$ & $2.53 \pm 0.40$ & $21.99 \pm 21.46 \dagger$ & $21.86 \pm 20.13$ \\
\hline $\mathrm{O}_{2}$ content $(\mathrm{mM})$ & $2.60 \pm 0.78$ & $2.86 \pm 0.89$ & $6.04 \pm 1.04 \dagger$ & $6.05 \pm 1.18$ \\
\hline Glucose $(\mathrm{mM})$ & $1.05 \pm 0.29$ & $1.33 \pm 0.29 \dagger$ & $1.42 \pm 0.34$ & $1.41 \pm 0.56$ \\
\hline Lactate $(\mathrm{mM})$ & $3.27 \pm 1.97$ & $3.84 \pm 1.96$ & $4.22 \pm 2.07$ & $3.56 \pm 1.83$ \\
\hline Ascending Ao & (14) & (14) & (14) & (10) \\
\hline $\mathrm{O}_{2}$ content $(\mathrm{mM})$ & $3.06 \pm 0.90$ & $3.15 \pm 0.99$ & $6.23 \pm 1.15 \dagger$ & $6.49 \pm 1.26$ \\
\hline Glucose (mM) & $1.08 \pm 0.30$ & $1.39 \pm 0.33 \div$ & $1.42 \pm 0.35$ & $1.46 \pm 0.56$ \\
\hline Lactate (mM) & $3.47 \pm 2.03$ & $4.05 \pm 2.07$ & $4.34 \pm 2.00$ & $3.81 \pm 1.72$ \\
\hline Umbilical vein & $(11)$ & (11) & (11) & \\
\hline $\mathrm{O}_{2}$ content $(\mathrm{mM})$ & $4.66 \pm 0.82$ & $4.83 \pm 0.93$ & $6.10 \pm 0.94 \dagger$ & NA \\
\hline Glucose $(\mathrm{mM})$ & $1.22 \pm 0.29$ & $1.45 \pm 0.26$ & $1.52 \pm 0.38$ & NA \\
\hline Lactate $(\mathrm{mM})$ & $3.74 \pm 2.27$ & $4.36 \pm 2.12$ & $4.82 \pm 2.16$ & NA \\
\hline
\end{tabular}

* Values in parentheses $=$ sample size. Ao, aorta; NA, sample not available.

$\dagger$ Significantly different from previous value, $p<0.001$.

$\ddagger$ Significantly different from previous value, $p<0.02$.

Table 2. Effect of birth-related events on maternal arterial blood

\begin{tabular}{lcccc}
\hline & Control & \multicolumn{4}{c}{ Ventilation } & Oxygenation & Occlusion \\
\hline$n$ & 14 & 11 & 14 & 9 \\
$\mathrm{pH}$ & $7.53 \pm 0.04$ & $7.52 \pm 0.03$ & $7.51 \pm 0.04$ & $7.52 \pm 0.04$ \\
$\mathrm{PCO}_{2}(\mathrm{kPa})$ & $4.80 \pm 0.53$ & $4.80 \pm 0.40$ & $4.80 \pm 0.40$ & $4.80 \pm 0.67$ \\
$\mathrm{PO}_{2}(\mathrm{kPa})$ & $12.80 \pm 0.93$ & $12.66 \pm 0.93$ & $13.33 \pm 1.20$ & $12.53 \pm 1.20$ \\
$\mathrm{O}_{2}$ content $(\mathrm{mM})$ & $5.45 \pm 0.88$ & $5.52 \pm 0.68$ & $5.50 \pm 0.89$ & $5.45 \pm 0.60$ \\
$\mathrm{Glucose}(\mathrm{mM})$ & $2.48 \pm 0.50$ & $2.37 \pm 0.47$ & $2.33 \pm 0.46$ & $2.63 \pm 0.39$ \\
Lactate $(\mathrm{mM})$ & $0.87 \pm 0.20$ & $0.78 \pm 0.19$ & $0.77 \pm 0.20$ & $0.80 \pm 0.37$ \\
\hline
\end{tabular}

$\mathrm{L}, 570 \pm 410 \mathrm{pmol} / \mathrm{L}$, and $890 \pm 780 \mathrm{pmol} / \mathrm{L}(1606 \pm 352,104$ \pm 76 , and $147 \pm 129 \mathrm{pg} / \mathrm{mL}$ ), respectively, during the control period. Ventilation increased norepinephrine concentration slightly to $15.74 \pm 11.40 \mathrm{nmol} / \mathrm{L}$ (NS) and increased epinephrine concentration to $5750 \pm 4880 \mathrm{pmol} / \mathrm{L}(p<0.05)$, but had no significant effect on plasma dopamine concentration. During oxygenation and cord occlusion, fetal plasma epinephrine concentrations remained elevated. Ventilation, oxygenation, and cord occlusion all had no effect on maternal catecholamine concentrations.

Total Fetal Uptake of Oxygen and Substrates. To determine the net flux of oxygen, glucose, and lactate across the umbilicalplacental, cerebral, myocardial, and hindlimb circulations, we measured arteriovenous concentration differences for these substances. The variance of the arteriovenous concentration differences was consistent during the four periods of study for each of the vascular beds for each substrate (Fig. 1). Thus, the changes we observed in net uptake or release of substrates reflected a change in extraction or blood flow.

Blood flow to the umbilical-placental circulation was initially $145 \pm 60 \mathrm{ml} \cdot \mathrm{min}^{-1} \cdot \mathrm{kg}^{-1}$ fetal body weight and did not change significantly with ventilation and oxygenation (Fig. 2). Oxygen delivery to the fetus via the umbilical-placental circulation was initially $664 \pm 277 \mu \mathrm{mol} \cdot \mathrm{min}^{-1} \cdot \mathrm{kg}^{-1}$ fetal body weight and decreased slightly but not significantly with ventilation and oxygenation (Fig. 2). In contrast, oxygen uptake across the umbilical-placental circulation decreased from $285 \pm 60 \mu \mathrm{mol} \cdot \mathrm{min}^{-1}$. $\mathrm{kg}^{-1}$ fetal body weight $\left(6.38 \pm 1.34 \mathrm{ml} \cdot \mathrm{min}^{-1} \cdot \mathrm{kg}^{-1}\right)$ to $214 \pm 66$ $\mu \mathrm{mol} \cdot \mathrm{min}^{-1} \cdot \mathrm{kg}^{-1}$ fetal body weight $(p<0.02)$ during ventilation and to zero during oxygenation ( $p<0.0001$; Fig. 2). This indicates that oxygen taken up in the pulmonary circulation supported fetal oxygen requirements.

Glucose and lactate delivery to the fetus via the umbilicalplacental circulation did not change significantly during ventilation and oxygenation (Fig. 3). During the control period, glucose uptake was $12.8 \pm 6.5 \mu \mathrm{mol} \cdot \mathrm{min}^{-1} \cdot \mathrm{kg}^{-1}$ fetal body weight $\left(2.3 \pm 1.2 \mathrm{mg} \cdot \mathrm{min}^{-1} \cdot \mathrm{kg}^{-1}\right)$ and lactate uptake was 13.6
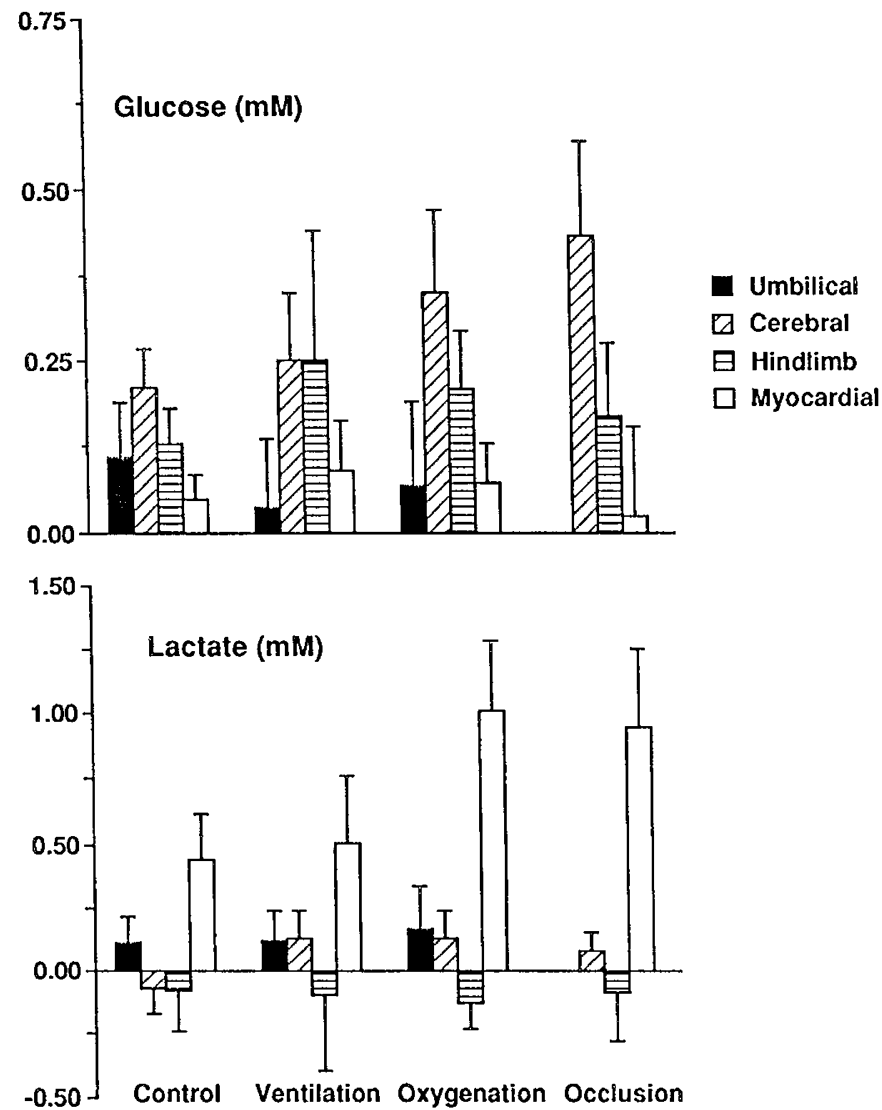

Fig. 1. Arteriovenous concentration differences for glucose and lactate across the umbilical, cerebral, hindlimb, and myocardial vascular beds is shown (mean $\pm \mathrm{SD}$ ). For each substrate for each vascular bed, the SD did not change significantly from one period to the next. Mean values did change, which indicates an effect of birth-related events on regional metabolism. In instances when the SD was large relative to the mean value, e.g. the hindlimb circulation and lactate arteriovenous difference, no significant flux was recorded.

$\pm 20.6 \mu \mathrm{mol} \cdot \mathrm{min}^{-1} \cdot \mathrm{kg}^{-1}\left(1.2 \pm 1.9 \mathrm{mg} \cdot \mathrm{min}^{-1} \cdot \mathrm{kg}^{-1}\right)$. Analysis of the substrate oxygen quotients revealed that glucose could account for a maximum of $30 \%$ of the oxidative metabolism of the fetus during the control period and lactate for $13 \%$. Fetal lactate uptake from the placenta was not significantly altered by ventilation or oxygenation (Fig. 3). In contrast, fetal glucose was not consistently derived from the maternal circulation. During 

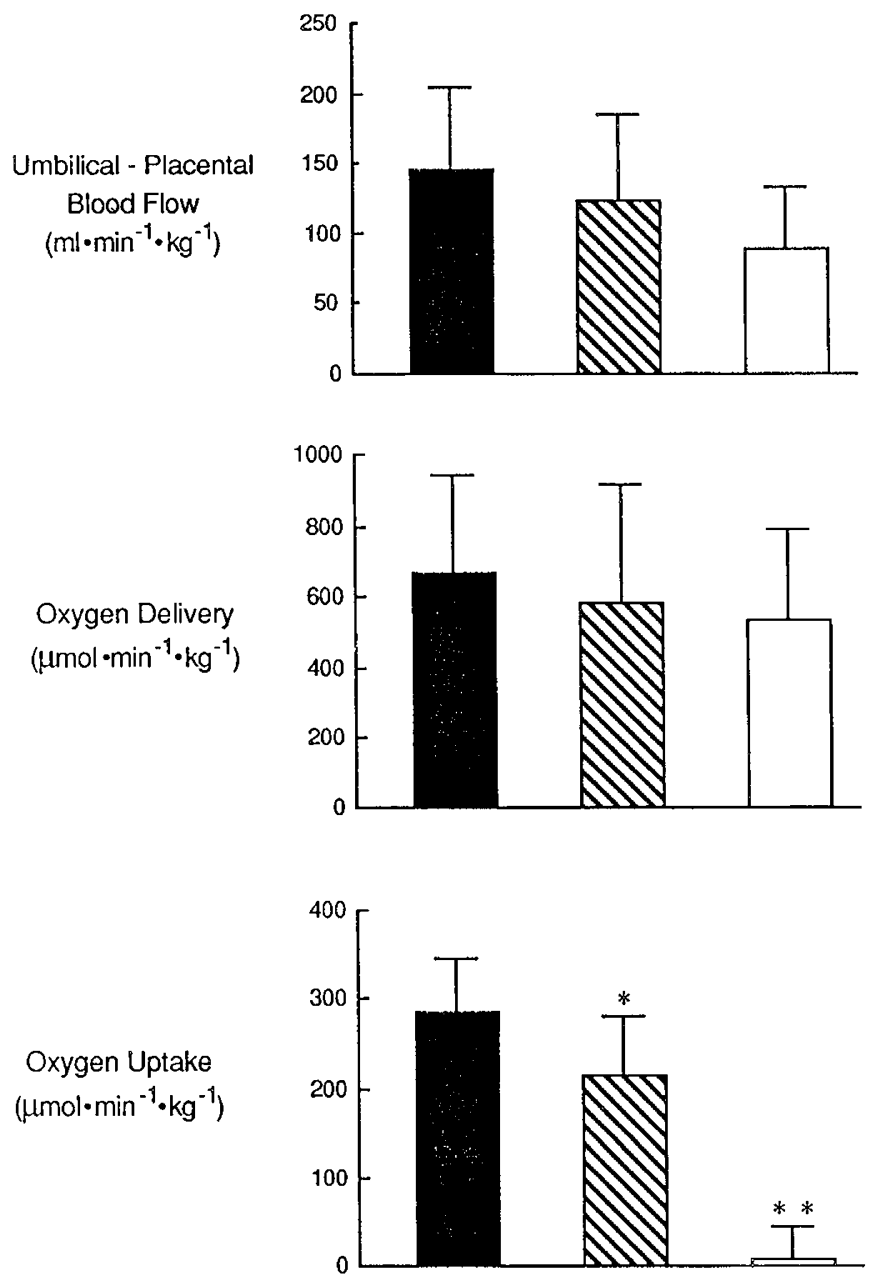

Fig. 2. Effect of ventilation and of oxygenation on umbilical-placental blood flow, oxygen delivery to the fetus and oxygen uptake by the fetus. Data are expressed as means +1 SD. Ventilation (striped bars) and oxygenation (open bars) decreased umbilical-placental blood flow slightly but not significantly below control values (black bars). Although oxygen delivery to the fetus was relatively stable throughout the experiment oxygen uptake by the fetus decreased from $285 \pm 60$ to $214 \pm 66 \mu \mathrm{mol}$. $\min ^{-1} \cdot \mathrm{kg}^{-1}$ fetal body weight $\left({ }^{*} p<0.02\right)$ during ventilation and to zero during oxygenation $(* * p<0.0001) . n=11$.

ventilation and during oxygenation, fetal glucose extraction and uptake decreased dramatically to zero (Fig. 3).

Regional Uptake of Oxygen and Substrates. Hindlimb metabolism. We have previously reported the effects of ventilation, oxygenation, and umbilical cord occlusion on regional blood flow distribution in the fetus (16). Thus, ventilation and oxygenation significantly decreased hindlimb blood flow (Table 3) Oxygen delivery decreased during ventilation and increased during oxygenation but oxygen extraction increased during ventilation and decreased with oxygenation, so oxygen consumption by the hindlimb was maintained (Table 3). Glucose uptake by the hindlimb was $1.97 \pm 0.80 \mu \mathrm{mol} \cdot \mathrm{min}^{-1} \cdot 100 \mathrm{~g}^{-1}$ during the control period. The glucose oxygen quotient was not different than 1 , which indicates that glucose oxidation could fully account for the oxygen consumed by the hindlimb (Table 3 ). Ventilation had no significant effect on hindlimb glucose metabolism, but oxygenation and cord occlusion decreased glucose uptake. The glucose oxygen quotient decreased to values significantly less than 1, which indicates that alternative substrates to glucose must have accounted for part of the oxidative metabolism of the hindlimb. A small amount of lactate was released from the hindlimb circulation throughout the experiment, but none of the values were different from zero (Table 3 ).
Cerebral metabolism. Cerebral blood flow decreased slightly during ventilation, and this caused cerebral oxygen delivery to fall. Oxygen extraction did not change, so oxygen consumption decreased during ventilation (Table 4). During oxygenation and cord occlusion, cerebral blood flow was significantly lower than during the control period, but because arterial oxygen content was increased, cerebral oxygen delivery did not change. Cerebral oxygen extraction and consumption were also not significantly altered. The fetal brain consumed considerable quantities of glucose throughout the experimental period, consistent with previous reports that glucose is the principle substrate for the fetal brain. As blood flow fell during oxygenation, glucose delivery decreased to less than half the values during ventilation. Cerebral extraction of glucose increased moderately but glucose consumption fell (Table 4). During the control period and during oxygenation and occlusion, the glucose oxygen quotient was significantly less than 1 (Table 4). This suggests that the fetal brain oxidized substrates other than glucose. Lactate delivery to the cerebral circulation was variable during the control and ventilation periods and decreased, although not significantly, as blood flow decreased during oxygenation (Table 4). During ventilation, a variable amount of lactate was taken up by the fetal brain, but during the other periods, there was no net flux of lactate across the cerebral circulation (Table 4).

Myocardial metabolism. Myocardial blood flow did not change during ventilation, but decreased significantly during oxygenation and occlusion when arterial oxygen content increased (Table 5). Oxygen delivery to the myocardium was constant throughout the experiment. The myocardium extracted about $60 \%$ of the oxygen delivered and myocardial oxygen consumption was relatively stable throughout (Table 5). The myocardium consumed small amounts of glucose that could account for at most 12 to $17 \%$ of the oxidative metabolism of the left ventricular free wall. Glucose was probably not an important substrate for myocardial metabolism because the glucose oxygen quotient was not significantly different from zero during ventilation and occlusion, and insignificant amounts of glucose were taken up during occlusion. Lactate was an important substrate for myocardial metabolism in this study. During the control period, lactate oxidation could account for a majority of the oxidative metabolism of the left ventricular free wall (Table 5 ). During oxygenation and cord occlusion, lactate delivery was significantly less than control values, but extraction increased significantly and lactate consumption rate was maintained (Table $5)$. During ventilation, oxygenation, and occlusion, lactate oxidation could account for $80 \%$ of the oxidative metabolism in the heart.

\section{DISCUSSION}

We sought to determine whether regional changes in oxygen and substrate utilization by the fetus were stimulated by ventilation, oxygenation, or umbilical cord occlusion and used a preparation described recently $(5,6,16,20-24)$ to examine the individual effects of these events in a single group of animals. We measured oxygen, glucose, and lactate uptake rates in the fetal hindlimb, myocardium, and brain. With the assumption that hindlimb metabolism is indicative of metabolism in fetal skin, muscle and bone, we obtained an estimate of metabolism of $80 \%$ of fetal mass.

At birth, the requirement for oxygen and exogenous substrates increases dramatically $(1,2,3,7)$. We have shown that ventilation of the lungs, an increase in oxygen delivery to the fetus, or umbilical cord occlusion were not important factors that increase oxygen consumption at birth. An increase in adrenergic activity has been reported to occur at birth (25-27), and increased norepinephrine concentrations in fetal sheep have been shown to increase oxygen consumption (28). Although fetal catecholamine concentrations increased with ventilation and oxygenation; these changes alone were insufficient to increase fetal oxy- 

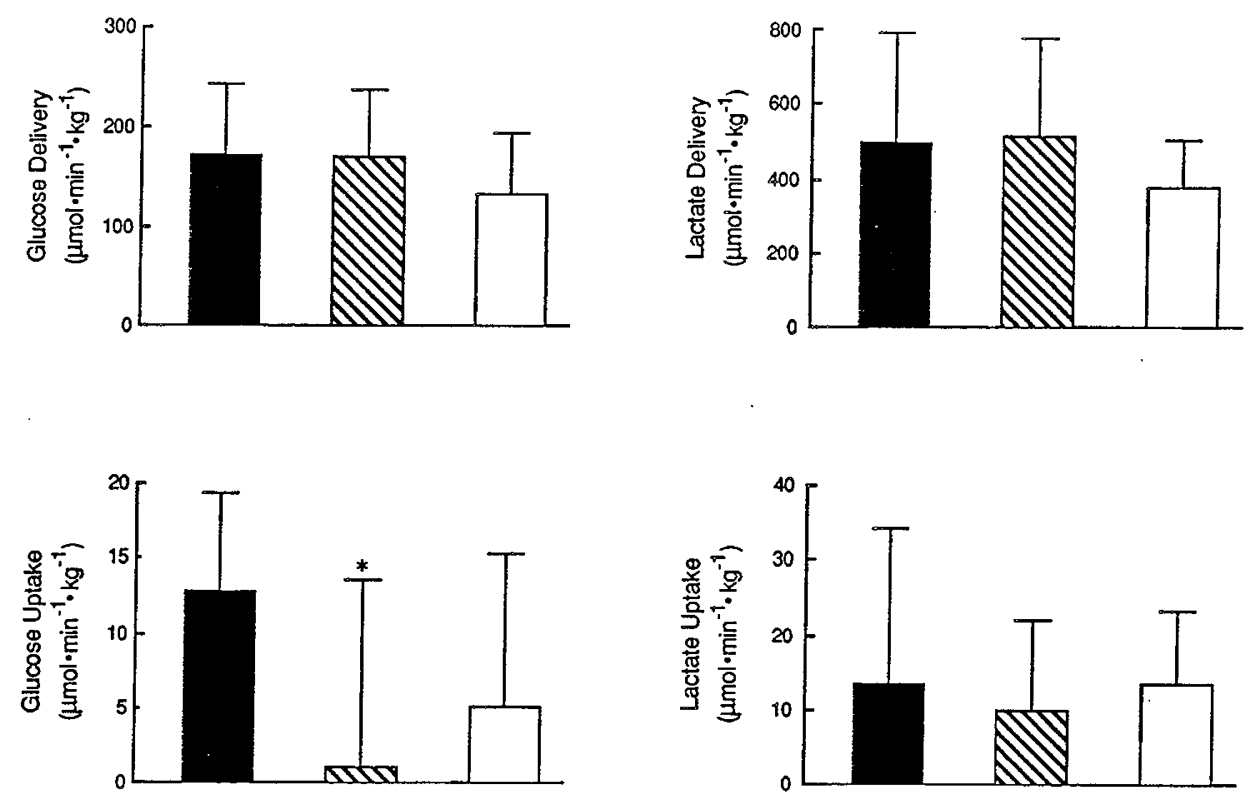

Fig. 3. Glucose and lactate delivery to and uptake by the fetus during ventilation and oxygenation. Delivery of glucose and of lactate to the fetus during the control (black bars), ventilation (striped bars), and oxygenation (open bars) periods were relatively stable. Uptake of glucose by the fetus decreased significantly to zero $(p<0.02)$. Subsequent oxygenation increased this value slightly but not significantly. Lactate uptake by the fetus was relatively low but stable throughout the experimental period. $n=11$.

Table 3. Fetal hindlimb blood flow and oxygen, glucose, and lactate delivery, extraction, and consumption*

\begin{tabular}{|c|c|c|c|c|}
\hline & Control & Ventilation & Oxygenation & Occlusion \\
\hline$n$ & 14 & 14 & 14 & 11 \\
\hline Blood flow & $15 \pm 3$ & $10 \pm 4 \dagger$ & $7 \pm 4 \ddagger$ & $9 \pm 3$ \\
\hline \multicolumn{5}{|l|}{ Oxygen } \\
\hline Delivery & $38 \pm 12$ & $26 \pm 11 \dagger$ & $40 \pm 21+$ & $52 \pm 33$ \\
\hline Extraction & $38 \pm 15$ & $51 \pm 12 \ddagger$ & $31 \pm 12 \dagger$ & $34 \pm 17$ \\
\hline Consumption & $14 \pm 5$ & $14 \pm 7$ & $12 \pm 8$ & $17 \pm 1$ \\
\hline \multicolumn{5}{|l|}{ Glucose } \\
\hline Delivery & $16 \pm 6$ & $13 \pm 6$ & $10 \pm 6$ & $13 \pm 10$ \\
\hline Extraction & $13 \pm 5$ & $20 \pm 11$ & $15 \pm 7$ & $12 \pm 5$ \\
\hline Consumption & $1.97 \pm 0.8$ & $2.3 \pm 1.1$ & $1.3 \pm 0.6 \dagger$ & $1.6 \pm 0.5$ \\
\hline Glucose $/ \mathrm{O}_{2}$ & $0.94 \pm 0.40$ & $1.15 \pm 0.78$ & $0.77 \pm 0.36 \S$ & $0.61 \pm 0.47 \S$ \\
\hline \multicolumn{5}{|l|}{ Lactate } \\
\hline Delivery & $53 \pm 37$ & $39 \pm 28$ & $32 \pm 35$ & $32 \pm 24$ \\
\hline Extraction & NS & NS & NS & NS \\
\hline Consumption & NS & NS & NS & NS \\
\hline
\end{tabular}

${ }^{*} \mathrm{NS}$, not significantly different from zero. Units for blood flow are $\mathrm{mL} \cdot \mathrm{min}^{-1} \cdot 100 \mathrm{~g}^{-1}$ organ wet weight, for delivery and consumption are $\mu \mathrm{mol} \cdot \mathrm{min}^{-1} \cdot 100 \mathrm{~g}^{-1}$ organ wet weight, and for extraction are percentages. Glucose $/ \mathrm{O}_{2}$ is a dimensionless value.

$\dagger$ Significantly different from previous value, $p<0.005$.

$\ddagger$ Significantly different from previous value, $p<0.05$.

$\S$ Value is $<1.0, p<0.03$.

gen consumption. Cooling is an important factor that increases oxygen consumption alone and in combination with oxygenation and umbilical cord occlusion $(5,6)$. Other important factors are increases in muscle activity and organ function and normal prenatal thyroid function, which is essential for the postnatal rise in oxygen consumption (3).

Umbilical glucose uptake decreased dramatically auring ventilation and remained low. However, glucose uptake by the fetal hindlimb, brain, and myocardium did not change appreciably and exceeded umbilical uptake. Thus, for a short period of time, at least, elimination of the umbilical supply of glucose does not affect glucose metabolism in the fetus. It is unlikely that the glucose utilized by the fetus was derived from gluconeogenesis. It has been shown previously that ventilation and oxygenation does not stimulate fetal gluconeogenesis (21). In our present
Table 4. Fetal cerebral blood flow and oxygen, glucose, and lactate delivery, extraction, and consumption*

\begin{tabular}{lcccc}
\hline & Control & Ventilation & Oxygenation & Occlusion \\
\hline$n$ & 7 & 7 & 7 & 3 \\
Blood flow & $144 \pm 60$ & $102 \pm 46$ & $46 \pm 18 \dagger$ & $48 \pm 6$ \\
Oxygen & & & & \\
$\quad$ Delivery & $402 \pm 132$ & $274 \pm 91 \ddagger$ & $286 \pm 74$ & $330 \pm 31$ \\
Extraction & $44 \pm 5$ & $41 \pm 15$ & $49 \pm 11$ & $44 \pm 14$ \\
$\quad$ Consumption & $173 \pm 48$ & $104 \pm 30 \dagger$ & $140 \pm 50$ & $145 \pm 46$ \\
Glucose & & & & \\
$\quad$ Delivery & $138 \pm 40$ & $146 \pm 77$ & $61 \pm 19 \S$ & $85 \pm 32$ \\
Extraction & $16 \pm 6$ & $18 \pm 7$ & $25 \pm 8 \ddagger$ & $25 \pm 10$ \\
Consumption & $20.9 \pm 4.7$ & $22.7 \pm 8.7$ & $15.2 \pm 5.0 \dagger$ & $19.9 \pm 4.3$ \\
Glucose/O & $0.77 \pm 0.24 \|$ & $1.34 \pm 0.45 \S$ & $0.68 \pm 0.21 \ddagger$ & $0.85 \pm 0.19$ \\
Lactate & \multicolumn{4}{c}{} \\
Delivery & $604 \pm 456$ & $542 \pm 499$ & $237 \pm 191$ & $275 \pm 33$ \\
Extraction & $\mathrm{NS}$ & $2.8 \pm 2.3$ & $2.7 \pm 1.6$ & $\mathrm{NS}$ \\
Consumption & $\mathrm{NS}$ & $14 \pm 11$ & $4.9 \pm 3.4$ & $\mathrm{NS}$ \\
Lactate/O & $\mathrm{NS}$ & $\mathrm{NS}$ & $0.12 \pm 0.08$ & $\mathrm{NS}$ \\
\hline
\end{tabular}

*NS, not significantly different from zero. Units for blood flow are $\mathrm{mL} \cdot \mathrm{min}^{-1} \cdot 100 \mathrm{~g}^{-1}$ organ wet weight, for delivery and consumption are $\mu \mathrm{mol} \cdot \mathrm{min}^{-1} \cdot 100 \mathrm{~g}^{-1}$ organ wet weight, and for extraction are percentages. Glucose $/ \mathrm{O}_{2}$ and lactate $/ \mathrm{O}_{2}$ are dimensionless values.

$\uparrow$ Significantly different from previous value, $p<0.01$.

$\ddagger$ Significantly different from previous value, $p<0.005$.

$\S$ Significantly different from previous value, $p<0.05$.

$\|$ Value is $<1.0, p<0.05$.

study, plasma epinephrine concentrations increased during ventilation to values shown to increase fetal blood glucose concentrations (29). Epinephrine probably stimulated glycogenolysis either directly or indirectly, by decreasing insulin and increasing glucagon concentrations $(30,31)$. As a result, fetal glucose concentrations increased significantly, altering the normal transplacental glucose gradient

The fetuses utilized significant portions of substrates other than glucose as indicated by an initial glucose oxygen quotient of 0.3 . Although it is generally accepted that umbilical glucose uptake normally accounts for approximately half of the fetal oxidative metabolic requirement (2), in late gestation, when we did these studies, glucose uptake is low relative to oxygen uptake, 
Table 5. Fetal myocardial blood flow and oxygen, glucose, and lactate delivery, extraction, and consumption*

\begin{tabular}{lcccc}
\hline & Control & Ventilation & Oxygenation & Occlusion \\
\hline$n$ & 8 & 8 & 8 & 5 \\
Blood flow & $229 \pm 90$ & $193 \pm 81$ & $91 \pm 34 \dagger$ & $92 \pm 52$ \\
Oxygen & & & & \\
$\quad$ Delivery & $708 \pm 275$ & $585 \pm 272$ & $602 \pm 179$ & $543 \pm 220$ \\
$\quad$ Extraction & $64 \pm 8$ & $67 \pm 13$ & $58 \pm 10$ & $57 \pm 10$ \\
$\quad$ Consumption & $464 \pm 183$ & $412 \pm 237$ & $314 \pm 97$ & $323 \pm 152$ \\
Glucose & & & & \\
$\quad$ Delivery & $234 \pm 119$ & $271 \pm 146$ & $136 \pm 59 \ddagger$ & $129 \pm 102$ \\
$\quad$ Extraction & $4 \pm 3$ & $6 \pm 4$ & $5 \pm 4$ & $\mathrm{NS}$ \\
$\quad$ Consumption & $9.7 \pm 7.4$ & $16.2 \pm 14.8$ & $6.3 \pm 5.3$ & $\mathrm{NS}$ \\
$\quad$ Glucose/O & $0.17 \pm 0.15$ & $\mathrm{NS}$ & $0.12 \pm 0.08$ & $\mathrm{NS}$ \\
Lactate & & & & \\
$\quad$ Delivery & $742 \pm 717$ & $756 \pm 425$ & $381 \pm 201 \ddagger$ & $323 \pm 198$ \\
$\quad$ Extraction & $19 \pm 10$ & $15 \pm 10$ & $27 \pm 10 \ddagger$ & $27 \pm 11$ \\
Consumption & $101 \pm 44$ & $91 \pm 57$ & $91 \pm 34$ & $87 \pm 48$ \\
$\quad$ Lactate/O & $0.63 \pm 0.11$ & $0.79 \pm 0.51$ & $0.85 \pm 0.18$ & $0.78 \pm 0.15$ \\
\hline
\end{tabular}

* NS, not significantly different from zero. Units for blood flow are $\mathrm{mL} \cdot \mathrm{min}^{-1} \cdot 100 \mathrm{~g}^{-1}$ organ wet weight, for delivery and consumption are $\mu \mathrm{mol} \cdot \mathrm{min}^{-1} \cdot 100 \mathrm{~g}^{-1}$ organ wet weight, and for extraction are percentages. Glucose $/ \mathrm{O}_{2}$ and lactate $/ \mathrm{O}_{2}$ are dimensionless values.

$\dagger$ Significantly different from previous value, $p<0.005$.

$¥$ Significantly different from previous value, $p<0.03$.

and the fetus uses larger proportions of substrates other than glucose (32). During oxygenation and during occlusion, glucose uptake relative to oxygen uptake decreased significantly in all of the organs studied. Thus, although the fetal hindlimb and brain normally consume only glucose and the fetal myocardium utilizes glucose as a main substrate $(11,14,33-36)$, it was evident that other substrates were utilized by these organs in these studies. Lactate oxidation accounted for at most $13 \%$ of total fetal oxidative metabolism in these studies, of which about half was consumed by the myocardium. Thus, it is clear that the fetuses utilized significant portions of alternate substrates. Possible sources of alternate substrates include local glycogen and fat stores, circulating amino acids, and endogenous production of glucose. Amino acid oxidation, which normally accounts for a quarter of fetal oxidative metabolism (2), may have been significantly greater in the present study, but we did not measure this variable.

Glycogen content in myocardium and skeletal muscle ranges from 20 to $30 \mathrm{mg} / \mathrm{g}$ wet weight of tissue in late gestation fetal sheep (37). This glycogen may be an important source of glucose for oxidation in the myocardium in these studies. Local glycogen stores were probably not an important energy source for the brain because only small amounts are normally present in the fetal sheep brain (37).

Amino acids could have supplied the fetus and individual fetal organs with a greater proportion of energy substrate during oxygenation and cord occlusion. Umbilical uptake of amino acids is an important energy source for the fetus, particularly when glucose uptake is reduced $(2,38,39)$. Increases in plasma epinephrine concentrations significantly increase $\alpha$-amino nitrogen concentrations in late-gestation fetal sheep (31), so it is likely that amino acid delivery to fetal organs increased in the present study. The fetal hindlimb normally takes up significant quantities of amino acids $(33,40)$ (Iwamoto HS, unpublished observations), particularly during periods of reduced glucose supply (33, 40, 41 ). In addition, there is evidence that the fetal brain can metabolize amino acids (42). It is thus possible that amino acids in the hindlimb and brain became an important energy source when glucose uptake was reduced.

Alternatively, fatty acid utilization by fetal tissues may have increased during these studies. Although fats are poorly transferred across the ovine placenta and ketoacids are not available in abundance, previously synthesized endogenous fat stores could be used as a substrate source. Oxygenation and umbilical cord occlusion during intrauterine cooling increase plasma FFA and glycerol concentrations $(5,6)$. Plasma epinephrine concentrations increased in the present study above the threshold required for lipolysis (29). The fetal heart and skeletal muscle have the capacity to metabolize fatty acids and ketones (42). However, the extent to which fatty acids and ketones contributed to regional oxidative metabolism was not determined in this study.

In conclusion, these studies have demonstrated that the birthrelated events, ventilation, oxygenation, and umbilical cord occlusion, have no effect on total fetal oxygen consumption or oxygen uptake by individual fetal organs. However, ventilation, oxygenation, and umbilical cord occlusion have significant effects on fetal glucose production, uptake, and utilization. The changes in glucose uptake occur independently of maternal glucose concentrations. This has important implications regarding the ability of the newborn to adapt to postnatal changes in available substrates.

\section{REFERENCES}

1. Lister G, Walter TK, Versmold HT, Dallman PR, Rudolph AM 1979 Oxygen delivery in lambs: cardiovascular and hematologic development. Am J Physiol 237:H668-H675

2. Battaglia FC, Meschia G 1978 Principle substrates of fetal metabolism. Physiol Rev 58:499-527

3. Breall JA, Rudolph AM, Heymann MA 1984 Role of thyroid hormone in postnatal circulatory and metabolic adjustments. J Clin Invest 73:14181424

4. Alexander G, Williams D 1970 Summit metabolism and cardiovascular function in young lambs during hyperoxia and hypoxia. J Physiol (Lond) 208:8597

5. Power GG, Gunn TR, Johnston BM, Nichols G, Gluckman PD 1989 Umbilical cord occlusion but not increased plasma $T_{3}$ or norepinephine stimulate brown adipose tissue thermogenesis in the fetal sheep. J Dev Physiol 11:171177

6. Power GG, Gunn TR, Johnston BM, Gluckman PD 1987 Oxygen supply and the placenta limit thermogenic responses in fetal sheep. J Dev Physiol 63:1896-1901

7. Sidi D, Kuipers JRG, Heymann MA, Rudolph AM 1983 Effects of ambient temperature on oxygen consumption and the circulation in newborn lambs at rest and during hypoxemia. Pediatr Res 17:254-258

8. Battaglia FC, Meschia G, Makowski EL, Bowes W 1968 The effect of maternal oxygen inhalation upon fetal oxygenation. J Clin Invest 47:548-555

9. Edelstone DI, Peticca BB, Goldblum LJ 1985 Effects of maternal oxygen administration on fetal oxygenation during reductions in umbilical blood flow in fetal lambs. Am J Obstet Gynecol 152:351-358

10. Comline RS, Silver M 1972 The composition of foetal and maternal blood during parturition in the ewe. J Physiol (Lond) 222:233-256

11. Fisher DJ, Heymann MA, Rudolph AM 1980 Myocardial oxygen and carbohydrate consumption in fetal lambs in utero and in adult sheep. Am J Physiol 238:H399-H405

12. Fisher DJ, Heymann MA, Rudolph AM 1981 Myocardial consumption of oxygen and carbohydrates in newborn sheep. Pediatr Res 15:843-846

13. Iwamoto HS, Oh W, Rudolph AM 1985 Renal metabolism in fetal and newborn sheep. In: Jones CT (ed) The Physiological Development of the Fetus and Newborn. Academic Press, London, pp 37-40

14. Jones Jr MD, Burd LI, Makowski EL, Meschia G, Battaglia FC 1975 Cerebral metabolism in sheep: a comparative study of the adult, the lamb, and the fetus. Am J Physiol 229:235-239

15. Rudolph AM 1984 Oxygenation in the fetus and neonate: a perspective. Semin Perinatol 8:158-167

16. Iwamoto HS, Teitel D, Rudolph AM 1987 Effect of birth-related events on blood flow distribution. Pediatr Res 22:634-640

17. Heymann MA, Payne BD, Hoffman JIE, Rudolph AM 1977 Blood flow measurements with radionuclide-labeled particles. Prog Cardiovasc Dis 20:55-79

18. Baer RW, Payne BA, Verrier ED, Vlahakes GJ, Molodowitch D, Uhlig PN, Hoffman JIE 1984 Increased number of myocardial blood flow measurements with radionuclide-labeled microspheres. Am J Physiol 246: $\mathrm{H} 418$ $\mathrm{H} 434$

19. Iwamoto HS, Kaufman T, Keil LC, Rudolph AM 1989 Responses to acute hypoxemia in fetal sheep at 0.6-0.7 gestation. Am J Physiol 256:H613H620

20. Teitel D, Iwamoto HS, Rudolph AM 1987 Effects of birth-related events on central blood flow patterns. Pediatr Res 22:557-566

21. Gleason CA, Rudolph AM 1986 Oxygenation does not simulate hepatic gluconeogenesis in fetal lambs. Pediatr Res 20:532-535

22. Gleason CA, Jones Jr MD, Traystman RJ, Notter RH 1988 Fetal cerebral responses to ventilation and oxygenation in utero. Am J Physiol 255:R 1049R 1054

23. Willis DM, Anderson DF, Thornburg KL, Faber JJ 1985 Alteration of arterial 
gas composition by positive pressure ventilation in the unanesthetized fetal lamb in utero. Biol Neonate 47:295-304

24. Blanco CE, Hanson MA, McCooke HB 1988 Effects on carotid chemoreceptor resetting of pulmonary ventilation in the fetal lamb in utero. $J$ Dev Physiol 10:167-174

25. Agata Y, Padbury JF, Ludlow JK, Polk DH, Humme JA 1986 The effect of chemical sympathectomy on catecholamine release at birth. Pediatr Res 20:1338-1344

26. Padbury J, Agata Y, Ludlow J, Ikegami M, Baylen B, Humme J 1987 Effect of fetal adrenalectomy on catecholamine release and physiologic adaptation at birth in sheep. J Clin Invest 80:1096-1103

27. Birk E, Rudolph AM, Roberts JM 1988 Fetal thyroidectomy reduces postnatal myocardial beta-adrenergic receptor responses in newborn lambs. Pediatr Res 23:431A(abstr)

28. Lorijn RHW, Longo LD 1980 Norepinephrine elevation in the fetal lamb: oxygen consumption and cardiac output. Am J Physiol 239:R115-R122

29. Padbury JF, Ludlow JK, Ervin MG, Jacobs HC, Humme JA 1987 Thresholds for physiologic effects of plasma catecholamines in fetal sheep. Am J Physiol 252:E530-E537

30. Sperling MA, Christensen RA, Ganguli S, Anand R 1980 Adrenergic modulation of pancreatic hormone secretion in utero: studies in fetal sheep. Pediatr Res 14:203-208

31. Jones CT, Ritchie JWK 1978 The metabolic and endocrine effects of circulating catecholamines in foetal sheep. J Physiol (Lond) 285:395-408

32. Boyd RD, Morriss Jr RH, Meschia E, Makowski EL, Battaglia FC 1973 Growth of glucose and oxygen uptakes by fetuses of fed and starved ewes. Am J Physiol 225:897-902

33. Liechty EA, Polak MJ, Lemons JA 1987 Branched-chain amino acid carbon and nitrogen arteriovenous concentration differences across the ovine fetal hindlimb. Pediatr Res 21:44-48

34. Morriss Jr FH, Boyd RDH, Makowski EL, Meschia G, Battaglia FC 1973 Glucose/oxygen quotients across the hindlimb of fetal lambs. Pediatr Res 7:794-797

35. Singh S, Sparks JW, Meschia G, Battaglia FC, Makowski EL 1984 Comparison of fetal and maternal hind limb metabolic quotients in sheep. Am J Obstet Gynecol 149:441-449

36. Wilkening RB, Molina RD, Battaglia FC, Meschia G 1987 Effect of insulin on glucose/oxygen and lactate/oxygen quotients across the hindlimb of fetal lambs. Biol Neonate 51:18-23

37. Shelley HJ 1960 Blood sugars and tissue carbohydrates in foetal and infant lambs and rhesus monkeys. J Physiol (Lond) 153:527-552

38. van Veen LCP, Teng C, Hay Jr WW, Meschia G, Battaglia FC 1987 Leucine disposal and oxidation rates in the fetal lamb. Metabolism 36:48-53

39. Lemons JA, Schreiner RL 1983 Amino acid metabolism in the ovine fetus. Am J Physiol 244:E459-E466

40. Liechty EA, Lemons JA 1984 Changes in ovine fetal hindlimb amino acid metabolism during maternal fasting. Am J Physiol 246:E430-E435

41. Lemons JA, Liechty EA 1987 Nitrogen flux across ovine maternal and fetal hindquarters during fasting. J Dev Physiol 9:151-158

42. Jones CT, Rolph TP 1985 Metabolism during fetal life: a functional assessment of metabolic development. Physiol Rev 65:357-430 